\title{
The Psychiatric Nurses Association
}

\author{
Denis M. Cox, Press Officer (PNA), Broadgate Hospital, Beverley, East Yorkshire
}

The Psychiatric Nurses Association (PNA) is a professional association, solely devoted to psychiatric and mental handicap nursing. A rapidly expanding organization, its origins are traced to the autumn of 1980 . Mr Seamus Killen, RMN, SRN (Littlemore Hospital, Oxford) attempted, through the columns of the Nursing Press, to measure support for a professional organization and the concept met with tremendous interest from psychiatric nurses all over the United Kingdom.

A meeting to discuss the formation of the PNA was held in October 1981. A steering executive committee was formed to prepare a constitution and to make proposals to the first annual general meeting which was held six months later, in April 1982. The constitution and rules of association were then adopted. The major aims and objectives of the association are: (1) To advance the practice and skill of all nurses working with the mentally ill and mental handicap patient in order to maintain, and wherever possible, improve standards of patient care; (2) To reflect the views of the members on issues and policies affecting the professional and clinical role of psychiatric nurses; (3) To promote the interests of psychiatric and mental handicap nursing and to enhance the status of its members.

The following were elected to office for a period of two years:

President-Mr A. F. Morley (Director of Nursing Services, St Nicholas Hospital, Gosforth, Newcastle); ViceChairman-Mr J. S. Watson (Divisional Nursing Officer, Fulbourn Hospital, Cambridge); Secretary-Mr S. B. Killen (Director of Nursing Services, Littlemore Hospital, Oxford); and Treasurer-Mr D. Smith (Director of Nursing, St Andrew's Hospital, Northampton).

One of the major preoccupations of the PNA since its inception, has been to lead the fight for proper representation for mental health nurses within the provisions laid down in the Nurse and Midwives and Health Visitors Act 1979.

A petition circulated by the PNA obtained the signatures of 6,550 qualified nurses and called upon the United Kingdom Central Council (UKCC) for Nurses, Midwives and Health Visitors to set up statutory committees for psychiatric and mental handicap nurses, and further resulted in meetings with Mr Kenneth Clarke, MP, Minister of Health, Senior Officials of the UKCC and the English National Board to press the case for proper representation. Regrettably, all concerned continue to disregard the claims of mental health nurses, consequently choosing to ignore the views of 20 per cent of qualified nurses, especially puzzling in view of the statutory provisions afforded to Health Visitors and District Nurses under the same legislation.

In July 1982 an historic meeting took place in Liverpool with PNA colleagues from Scotland, Northern Ireland and Eire. Although operating independently, all four associations share common interests on topics such as standards of care, education and training, research, specialist groups and elections to respective national boards. It is anticipated that this international group will be formalized into a joint committee of Mental Health Nursing Organizations to enable representation with such bodies as the European Economic Community Commission, United Kingdom Central Council, the World Health Organization and other international bodies concerned with psychiatric care.

To provide a forum and to encourage the exchange of ideas the PNA, in conjunction with the Nursing Times, publishes a bi-monthly journal entitled Mental Health Nursing. which is circulated to all members. Seen as priority reading for every nurse working in the spicialty, it clearly allows an opportunity for communication unprecedented in the history of the profession.

The greatest strength of the PNA is the commitment of its members and much is to be achieved at clinical level. Since April 1982 regional and district branches have been formed in Yorkshire, Mersey, South Yorkshire, Northern, East Anglia, South East Thames, South Western, Oxford and the West Midlands, and well supported national and regional nursing conferences are taking place, providing the profession with the stimulus and communication network it so badly required.

Under the direction of the National Executive Committee, special interest groups concentrating on education, training, research, care of the elderly, alcohol/drug addiction, ethical issues and nursing in secure environments will provide a much needed source of reference and research.

The PNA has in its evolution, activated an unprecedented scrutiny of practice, and while it offers no simple explanations, the association has begun the process of questioning and challenging, in order to examine methods critically.

There is a richness of expertise beginning to emerge, and the PNA exists to nurture this and resist anything which may dilute standards of care. 